\title{
Pyrophosphate arthropathy: a study of metabolic associations and laboratory data*
}

\author{
G. M. ALEXANDER, P. A. DIEPPE, M. DOHERTY, AND D. G. I. SCOTT \\ From the Bristol Royal Infirmary and the Royal National Hospital for Rheumatic Diseases, Bath
}

SUMMARY 105 consecutive patients with pyrophosphate arthropathy have been studied. Disease associations and metabolic abnormalities were compared with those of an age and sex matched group of 105 acute medical admissions, and with 48 patients presenting with uncomplicated osteoarthritis. Patients with pyrophosphate arthropathy had a higher incidence of hypothyroidism (10), hyperparathyroidism (2), and chronic steroid therapy (15) than did those in the comparative groups. Laboratory data showed abnormalities suggesting chronic inflammatory disease in many patients, but no other unexpected metabolic findings. Metabolic abnormalities were uncommon in pyrophosphate arthropathy, and extensive metabolic screening of patients was unrewarding.

Pyrophosphate arthropathy (PA) is a well recognised condition which has been described under a variety of different names including pseudogout, chondrocalcinosis, and calcium pyrophosphate dihydrate (CPD) crystal deposition disease.$^{1-3}$ The cause of crystal deposition is unknown. A few cases are famil$\mathrm{ial}^{2} 4$ and others have been associated with a variety of metabolic diseases, including hyperparathyroidism, haemochromatosis, and hypophosphatasia. ${ }^{5-8}$ By inference these diseases are implicated in the pathogenesis of the deposits. Most reported associations have been based on a search for PA in patients with metabolic disease, but PA is common, especially in the elderly, ${ }^{5910}$ and there are no adequate large control series on the incidence of metabolic diseases in patients with PA. ${ }^{11} 12$

We have studied 105 consecutive unselected patients with PA whose clinical and radiological features have been previously described. ${ }^{13}$ This paper describes the metabolic abnormalities, disease associations, and laboratory investigations in these patients. For comparison we have studied a matched group of acute medical admissions (for disease associations) and 48 consecutive patients with uncomplicated osteoarthritis (disease associations and laboratory investigations).

\section{Patients and methods}

105 consecutive patients presenting to a rheumato-

Accepted for publication 20 July 1981.

* Presented to the Heberden Society in May 1981.

Correspondence to Dr P. A. Dieppe, Bristol Royal Infirmary, Marlborough Street, Bristol BS2 $8 \mathrm{HW}$. logist because of joint disease, associated with radiological and/or microscopic evidence of pyrophosphate deposition, were studied. The criteria for inclusion were as previously described. ${ }^{13} 105$ consecutive patients (age and sex matched) who were admitted to a local hospital with acute medical conditions, and 48 unselected patients with typical uncomplicated clinical and radiological osteoarthritis (OA) were also studied. The latter group had no evidence of CPD or hydroxyapatite crystal deposition disease.

A full medical history of past or present illness was taken from all the patients in order to compare the incidence of intercurrent disease in the 3 groups.

Laboratory investigations performed on the patients with PA and those with $\mathrm{OA}$ included haemoglobin, plasma viscosity, blood urea, sugar, urate, iron, total iron binding capacity, calcium, albumin, phosphate, alkaline phosphatase, thyroxine, free thyroxine index (TSH when indicated),

Table 1 Incidence of coexisting disease in patients with pyrophosphate arthropathy, osteoarthritis, and acute medical admissions (results expressed as a percentage)

\begin{tabular}{|c|c|c|c|}
\hline $\begin{array}{l}\text { Diagnosis } \\
\text { Number: }\end{array}$ & $\begin{array}{l}\text { Pyrophosphate } \\
\text { arthropathy } \\
105\end{array}$ & $\begin{array}{l}\text { Osteoarthritis } \\
48\end{array}$ & $\begin{array}{l}\text { Acute medical } \\
\text { admissions } \\
105\end{array}$ \\
\hline \multicolumn{3}{|l|}{ Rheumatoid } & 1.5 \\
\hline Hypothyroidism & 10.5 & $2 \cdot 1$ & $2 \cdot 8$ \\
\hline Hyperthyroidism & $3 \cdot 8$ & $2 \cdot 1$ & $2 \cdot 8$ \\
\hline $\begin{array}{l}\text { Hyperparathyroidism } \\
\text { Chronic steroid }\end{array}$ & 1.9 & 0 & 0 \\
\hline therapy & $15 \cdot 2$ & $\mathbf{0}$ & $2 \cdot 4$ \\
\hline Gout & $1 \cdot 9$ & 0 & $2 \cdot 4$ \\
\hline Hypertension & $18 \cdot 1$ & $8 \cdot 3$ & $15 \cdot 2$ \\
\hline Diebetes mellitus & $2 \cdot 8$ & 0 & $7 \cdot 6$ \\
\hline
\end{tabular}


Table 2 Laboratory findings in patients with pyrophosphate arthropathy and osteoarthritis (mean $\pm S D$ )

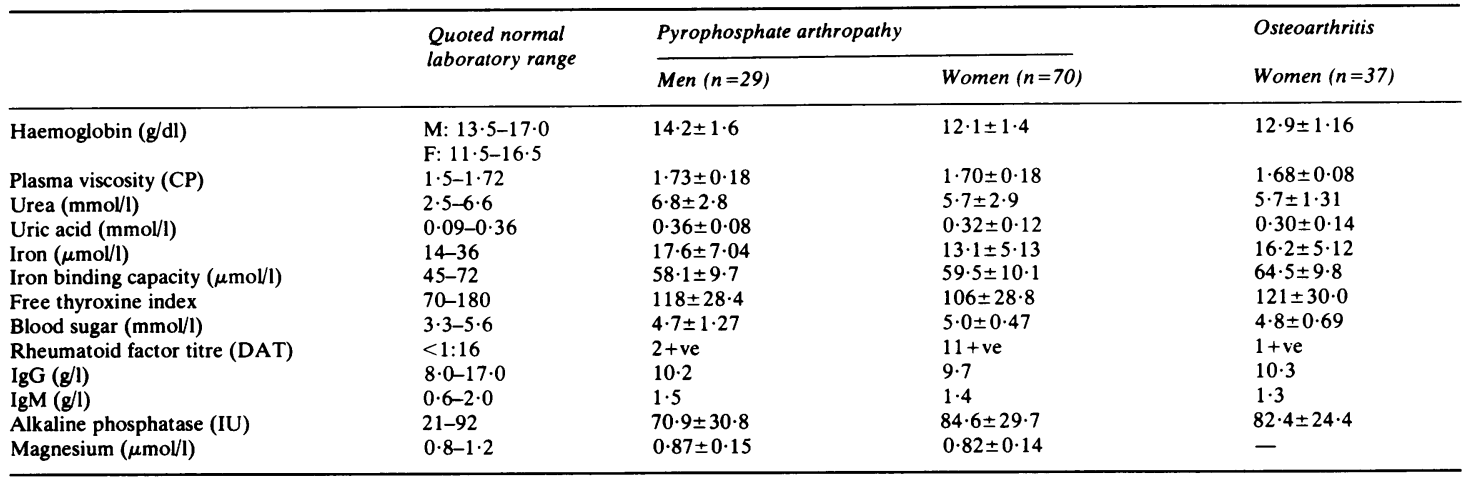

immunoglobulins $\mathrm{G}, \mathrm{A}$, and $\mathrm{M}$, IgM and $\operatorname{IgG}$ rheumatoid factor, and magnesium.

Calcium profiles were also performed on the serum of 105 different age and sex matched ambulant outpatients without rheumatic disease in whom the putative diagnosis would not be expected to influence calcium homoeostasis.

The 18 patients with PA aged under 60 years at presentation were studied in greater detail. Additional investigations in this group included fasting calcium, magnesium, and phosphate; 24-hour urine estimations of calcium, creatinine, magnesium, and phosphate excretion; HLA tissue typing; and fasting lipid profiles (low density, very low density, and high density lipoproteins).

\section{Results}

The clinical details of the 105 patients with PA have been described elsewhere. ${ }^{13}$ Briefly, 75 were women (mean age 73) and 28 men (mean age 62). Eighteen patients were less than 60 years old at presentation, and, of these, $12(67 \%)$ were men. The younger men constituted a distinct clinical subset, having more acute attacks and less chronic arthritis than the older women.

The 105 acute medical admissions were matched for age and sex with the PA group. The diagnoses necessitating admission were those expected in an aged population (predominantly cardiovascular disease). Of the 48 patients with OA 7 were men (mean age 65 years) and 41 women (mean age 66 years). The number of men with OA was too small for adequate analysis, and their laboratory data have not been included.

The major disease associations, based on the medical history of all three groups, are shown in Table 1.
The most notable difference in the PA group was the higher incidence of hypothyroidism, hyperparathyroidism, rheumatoid arthritis, and chronic steroid therapy when compared with the OA group or the acute medical admissions. Hypertension was more common in the PA group than the OA group, but not when compared with acute medical admissions. Diabetes mellitus was more common in acute medical admissions than either the PA or OA groups.

The laboratory data are shown in Tables 2,3 , and 4. Haematological indices suggesting a chronic inflammatory disorder (anaemia, raised plasma viscosity, low serum iron with normal or low iron binding capacity) were common in the PA group (Table 3 ). High blood urea levels were also more common in the PA group, and the mean levels were higher in both men and women with PA (Table 2) than the OA group $(\mathrm{p}<0 \cdot 01)$. These results are difficult to interpret, as more patients with PA were on treatments known to affect blood urea estimation (especially nonsteroidal anti-inflammatory drugs). No significant differences were found between the 2 groups for any of the other laboratory indices shown in Tables 2 and 3.

The calcium results are shown in Table 4, which compares the PA group, the OA group, and the outpatients laboratory control group (see 'Methods'). Calcium levels were corrected for an albumin of $40 \mathrm{mmol} / 1 .{ }^{14}$ Hypercalcaemia ( $\mathrm{Ca}>2 \cdot 7$ $\mathrm{mmol} / \mathrm{l}$ ) was found in 5 patients with PA, none with $\mathrm{OA}$, and only one of the control group. Hypocalcaemia $(\mathrm{Ca}<2.20 \mathrm{mmol} / \mathrm{l})$ was present in 12 patients with PA (predominantly older women), 3 with $\mathrm{OA}$, and 11 controls. A low phosphate was more common in controls than either the PA or OA groups. Absolute values showed no differences in mean Ca level between the 3 groups, although phosphate levels were highest in men with PA. Only the 
Table 3 Number of patients with laboratory findings outside the quoted normal ranges

\begin{tabular}{|c|c|c|c|}
\hline & \multicolumn{2}{|c|}{ Pyrophosphate arthropathy } & \multirow{2}{*}{$\begin{array}{l}\text { Osteoarthritis } \\
\text { Women }(n=37)\end{array}$} \\
\hline & $\operatorname{Men}(n=27)$ & Women $(n=70)$ & \\
\hline $\begin{array}{l}\text { Low haemoglobin } \\
\text { Raised plasma }\end{array}$ & $10 \cdot 7 \%$ & $19 \cdot 7 \%$ & $5 \cdot 4 \%$ \\
\hline $\begin{array}{l}\text { viscosity } \\
\text { Low iron with } \\
\text { normal or low iron }\end{array}$ & $50.0 \%$ & $40 \cdot 3 \%$ & $23 \cdot 7 \%$ \\
\hline binding & $15 \cdot 4 \%$ & $40.7 \%$ & $12.5 \%$ \\
\hline $\begin{array}{l}\text { Raised blood urea } \\
\text { Low free thyroxine }\end{array}$ & $33 \cdot 3 \%$ & $50 \cdot 8 \%$ & $11 \cdot 4 \%$ \\
\hline index & $3 \cdot 7 \%$ & $14 \cdot 3 \%$ & $2 \cdot 7 \%$ \\
\hline
\end{tabular}

increased incidence of hypercalcaemia in the PA group compared with either the OA group or controls reached statistical significance $(p<0 \cdot 01)$. Serum magnesium was estimated in 29 patients with $P A$ and was abnormal $(<0.70 \mathrm{mmol} / \mathrm{l})$ in 3 , all of whom were elderly women on diuretics.

Thirteen of the patients aged under 60 ( 9 men, 4 women) were studied in greater detail. 24-hour urine estimations of calcium, creatinine, magnesium, and phosphate excretion were normal in all patients. Apart from a persistently raised calcium in one man, all estimations of fasting serum calcium magnesium, phosphate, and lipoproteins fell within the normal ranges. Tissue typing was performed on 11 patients, but no significant HLA association was demonstrated (numbers were too small to allow analysis of low-order association).

\section{Discussion}

PA has been reported in association with a variety of metabolic diseases. ${ }^{5-8}$ Most studies have been based on the examination of patients with metabolic disease and have reported the concurrence of PA. PA is a common condition, especially in the elderly, ${ }^{910}$ and, when the metabolic disease is also common, associations by chance are likely and a significant association is difficult to prove. The occurrence of PA with rare diseases such as hypophosphatasia, hypomagnesaemia, or haemochromatosis suggests a genuine link or association, but in contrast gout, diabetes, and hypertension are common, affect a similar age group, and may thus not represent true disease associations with PA. Metabolic diseases have often been reported in association with PA, but controlled data are scarce. Control groups were included in 2 recent reports, but the numbers of patients studied were small. ${ }^{11}{ }^{12}$

We have studied a large number of patients with PA and compared the incidence of metabolic disease with 2 large 'control' groups. Patients with PA had a mean history of joint disease of over 10 years, and it would be reasonable to expect any associated metabolic disease to be manifest by the time of this study.

The choice of control groups for a study of PA is difficult. Patients with other arthritides may develop CPD deposition as a secondary phenomenon. We therefore examined our OA group carefully for radiological or synovial fluid evidence of CPD or hydroxyapatite crystals. These were not found, but we cannot exclude the possibility that some crystals were present in the tissues of some patients. Chondrocalcinosis may also be asymptomatic in the elderly and cannot be excluded in all of the acute medical admission group. We have therefore used the term 'comparative' rather than 'control' for the non-PA groups.

We were unable to obtain full metabolic screening of the acute medical admissions because of the severity of disease in some patients. We have therefore compared laboratory investigations in the PA and OA groups with the normal range from our local laboratory. Initial evaluation of the PA group showed a high incidence of abnormal calcium levels; we therefore assessed a second comparative group of 105 age and sex matched patients to check that this finding was genuine. Hypocalcaemia was common in

Table 4 Calcium/phosphate balance in pyrophosphate arthropathy, matched laboratory controls, and patients with osteoarthritis

\begin{tabular}{|c|c|c|c|c|c|}
\hline & \multicolumn{2}{|c|}{ Pyrophosphate arthropathy } & \multirow{2}{*}{$\begin{array}{l}\text { Osteoarthritis } \\
\begin{array}{l}\text { Women } \\
37\end{array}\end{array}$} & \multicolumn{2}{|l|}{ Controls } \\
\hline & $\begin{array}{l}\text { Women } \\
70\end{array}$ & $\begin{array}{l}\text { Men } \\
27\end{array}$ & & $\begin{array}{l}\text { Women } \\
70\end{array}$ & $\begin{array}{l}\text { Men } \\
27\end{array}$ \\
\hline \multicolumn{6}{|l|}{ (1) Normal levels } \\
\hline $\begin{array}{l}\text { Mean serum calcium } \\
\text { Mean serum phosphate }\end{array}$ & $\begin{array}{l}2 \cdot 36 \pm 0 \cdot 16 \\
1 \cdot 12 \pm 0 \cdot 18\end{array}$ & $\begin{array}{l}2 \cdot 34 \pm 0 \cdot 17 \\
1 \cdot 01 \pm 0 \cdot 18\end{array}$ & $\begin{array}{l}2 \cdot 35 \pm 0 \cdot 12 \\
1 \cdot 04 \pm 0 \cdot 14\end{array}$ & $\begin{array}{l}2 \cdot 36 \pm 0 \cdot 14 \\
1 \cdot 03 \pm 0 \cdot 21\end{array}$ & $\begin{array}{l}2 \cdot 36 \pm 0 \cdot 10 \\
1 \cdot 02 \pm 0 \cdot 21\end{array}$ \\
\hline \multicolumn{6}{|c|}{ (2) \% of patient with levels outside normal range } \\
\hline Hypercalcaemia & $4 \cdot 3 \%$ & $7 \cdot 4 \%$ & 0 & $1.4 \%$ & 0 \\
\hline Hypocalcaemia & $14 \cdot 3 \%$ & $7 \cdot 4 \%$ & $8 \cdot 1 \%$ & $10.0 \%$ & $14 \cdot 8 \%$ \\
\hline Hyperphosphatasia & $2.9 \%$ & $3.7 \%$ & $5.4 \%$ & $8.6 \%$ & $18 \cdot 5 \%$ \\
\hline
\end{tabular}


the control groups, but only one patient had hypercalcaemia. Therefore, of the established associations, only hyperparathyroidism was seen in this study. Two patients with PA had parathyroid adenomas resected at least 10 years prior to presentation. Five patients had mild hypercalcaemia, including one of those with proved parathyroid disease; and low-grade hyperparathyroidism could be present in the other 4 . Even 2 patients with definite parathyroid disease are a much higher number than the expected incidence of between 1:1000 and 1:20 000. ${ }^{15}{ }^{16}$ No patient with hypophosphatasia or haemochromatosis was identified in the PA group.

Low levels of magnesium have been reported in PA. ${ }^{17}$ Magnesium, like calcium, is a divalent iron, and the magnesium:calcium balance may be important in the formation and solubility of CPD crystals. Serum magnesium was low in 3 of the 29 patients in whom it was measured, but these patients were elderly women who were on diuretic therapy, and this may explain the low levels.

An association between PA and thyroid disease was first suggested in $1975 .{ }^{18}$ Thyroid disease is common in the elderly, but our incidence of $15 \%$ in patients with PA is considerably higher than the $3 \%$ quoted for an elderly population, ${ }^{19}$ and suggests a real association between these diseases. The mechanism of this association is unclear, but TSH is known to influence synovial membrane adenylate cyclase ${ }^{20}$ and is also thought to alter the composition of cartilage, ${ }^{20}$ which may be important for the deposition of CPD crystals.

The association between PA and chronic corticosteroid therapy may reflect a common therapeutic approach to arthritis. Other possible causes of this association include steroid-induced damage to articular cartilage predisposing to the deposition of CPD, or corticosteroids influencing cartilage metabolism to favour CPD deposition. This association has not been described previously.

Several patients in this study had another arthropathy, such as rheumatoid arthritis, as well as either hypothyroidism or chronic corticosteroid therapy. The combination of damaged articular cartilage plus an abnormal metabolic milieu may be of crucial importance to the development of PA.

Hypertension and diabetes mellitus were not found in association with PA in this study, and the previously reported associations may simply reflect the coexistence of 2 common conditions. Uraemia, though mild, was commoner in PA than in patients with $\mathrm{OA}$, but the differences in mean values were small. Over $60 \%$ of those with uraemia were taking nonsteroidal anti-inflammatory drugs, which may affect renal blood flow. ${ }^{21}$

The presence of an abnormal plasma viscosity, a sensitive indicator of inflammation, in over $40 \%$ of patients with PA together with low iron with a low or normal iron binding capacity (suggestive of chronic inflammation) is previously unreported but most probably represents crystal-induced inflammation.

Young patients with PA might be expected to have the highest incidence of associated metabolic diseases. However, careful metabolic investigation of our younger patients failed to reveal any increased incidence of metabolic abnormalities.

This study demonstrates that, of the reported metabolic associations with PA, only hypothyroidism and hyperparathyroidism are common. Chronic steroid therapy may also be important. Hypertension, diabetes mellitus, hyperuricaemia, and mild uraemia are probably related to age or drug treatment and not to PA.

Metabolic associations were present in a minority of patients with PA, whereas pre-existing cartilage damage from nonmetabolic causes was common.

Thorough laboratory investigations did not reveal unsuspected metabolic abnormalities except for 2 cases of mild, persistent hypercalcaemia. The diagnosis of metabolic disease in association with PA was made by a careful clinical history and examination in all cases, and we cannot recommend extensive laboratory investigation in patients with PA.

\footnotetext{
References

' McCarty D J, Kohn N N, Faires J S. The significance of calcium phosphate crystals in the synovial fluid of arthritic patients. 'The Pseudogout Syndrome'. I. Clinical aspects. Ann Intern Med 1962; 56: 711-37.

${ }^{2}$ Zitnan D, Sitaj S. Chondrocalcinosis articularis. Section I. Clinical and radiological study. Ann Rheum Dis 1963; 22: 142-52.

3 McCary D J. Calcium pyrophosphate dihydrate crystal deposition disease-1975. Arthritis Rheum 1976; 19: 275-85.

${ }^{4}$ Korst J K van der, Geerards J, Driessens F C M. A hereditary type of idiopathic articular chondrocalcinosis. Survey of a pedigree. Am J Med 1974; 56: 307-14.

${ }^{5}$ McCarty D J. Pseudogout; articular chondrocalcinosis. Calcium pyrophosphate crystal deposition disease. In: Hollander J L, McCarty D J, eds. Arthritis and Allied Conditions. 8th ed. Philadelphia: Lea and Febiger, 1972: 1140-60.

${ }^{6}$ Dymock I W, Hamilton E B D, Lavs J W, Williams R. Arthropathy of haemachromatosis. Ann Rheum Dis 1970; 29: 469-76.

7 O'Duffy J D. Hypophosphatasia associated with calcium pyrophosphate dihydrate deposits in cartilage. Arthritis Rheum 1970; 13: 381-7.

${ }^{8}$ Eade A W T, Swannell A J, Williamson N. Pyrophosphate arthropathy in hypophosphatasia. Ann Rheum Dis 1981; 40: 164-70.

9 Ellman M H, Levin B. Chondrocalcinosis in elderly persons. Arthritis Rheum 1975; 18: 43-7.

${ }^{10}$ Wilkins E, Dieppe P A, Maddison P, Evison G. Articular chondrocalcinosis and its association with osteoarthritis in the elderly. Ann Rheum Dis 1981; 40: 516.

11 McCarty D J, Silcox D C, Coe F. et al. Diseases associated with calcium pyrophosphate dihydrate crystal deposition. A controlled study. Am J Med 1974; 56: 704-14.

${ }^{12}$ Ellman M H, Brown N L, Porat P. Laboratory investigations in
} pseudogout patients and controls. J Rheumatol 1980; 7: 77-81. 
${ }^{13}$ Dieppe P A, Alexander G J M, Jones H E, et al. Pyrophosphate arthropathy: A clinical and radiological study of 105 cases. Ann Rheum Dis (paper in same issue).

14 Leading article: Correcting the calcium. Br Med J 1977; i: 598.

${ }^{15}$ Boonstra C E, Jackson C E. Serum calcium survey for hyperparathyroidism, results in 50000 clinic patients. Am J Clin Pathol 1977; 55: 523-32.

${ }^{16}$ Haff R C, Black W C, Ballinger W F. Primary hyperparathyroidism: changing clinical, surgical and pathologic aspects. Ann Surg 1970; 171: 85-96.

${ }^{17}$ Milazzo S C, Henderson D R F, Cleland C G. Calcium pyrophosphate dihydrate crystal deposition disease and familial hypomagnesaemia. XIV Int Congr Rheumatol San Francisco 1977 (abstract).
18 Dorwart B B, Schumacher H R. Joint effusions, chondrocalcinosis, and other rheumatic associations of hypothyroidism. Am J Med 1975; 59: 780-8.

19 Werner S C. Hypothydroidism. In: Werner S C, Ingbor S H, eds. The Thyroid. 3rd ed. New York: Harper and Row, 1977.

${ }^{20}$ Newcombe D S, Ortel R W, Levey G S. Activation of human synovial adenyl cyclase by thyroid stimulating hormone. Biochem Biophys Res Commun 1972; 48: 201-3.

${ }^{21}$ Prescott L F. Drug-induced renal disease-a clinical pharmacologist's view. Eur J Rheumatol Inflamm 1979; 3: 136-40.

We thank the Arthritis and Rheumatism Council for financial support. 